\title{
УДК 611:576.08
}

\section{РЕГИОНАЛЬНАЯ ГЕТЕРОГЕННОСТЬ АСТРОЦИТОВ В ОТНОШЕНИИ ЭКСПРЕССИИ ГЛИАЛЬНОГО ФИБРИЛЛЯРНОГО КИСЛОГО БЕЛКА И СИНТЕТАЗЫ ГЛУТАМИНА IN VITRO}

\author{
Тучина О.П. ${ }^{1}$, Адамовская С.С. ${ }^{1}$ \\ ${ }^{1}$ ФАОУ ВО «БФУ имени Иммануила Канта», Лаборатория синтетической биологии, Институт живых \\ систем, Калининград, е-mail: otuchina@kantiana.ru
}

Астроциты представляют собой морфологически и функционально неоднородную популяцию клеток. Большинство исследований посвящено изменениям глии при развитии нейродегенеративных заболеваний, однако гетерогенность клеток в физиологическом состоянии и при нормальном старении также представляет большой интерес для понимания нейрон-глиальных взаимодействий. Целью настоящего исследования было изучение регионально гетерогенной экспрессии двух часто используемых астроцитарных маркеров: глиального фибриллярного кислого белка (GFAP) и синтетазы глутамина (GS) - in vitro. Астроциты, выделенные из ствола мозга, подразделяются на две популяции: GFAP- и GFAP+, причем последние характеризуются повышенной экспрессией белка по сравнению с астроцитами, выделенными из церебральной коры и гиппокампа. В отношении экспрессии GS астроциты из церебральной коры демонстрируют существенно более высокий уровень GS по сравнению с астроцитами из гиппокампа и ствола мозга. При этом между экспрессией GFAP и GS наблюдается положительная корреляция для всех исследованных регионов мозга. Таким образом, наши данные свидетельствуют о том, что астроциты из церебральной коры, гиппокампа и ствола мозга регионально гетерогенны в отношении экспрессии GFAP и GS.

Ключевые слова: глиальные клетки, церебральная кора, гиппокамп, ствол мозга, GFAP, GS.

\section{REGIONAL HETEROGENEITY OF ASTROCYTES IN RESPECT TO GLIAL FIBRILLARY ACIDIC PROTEIN AND GLUTAMINE SYNTHETASE EXPRESSION IN VITRO}

\author{
Tuchina O.P. ${ }^{1}$, Adamovskaya S.S. ${ }^{1}$ \\ ${ }^{1}$ Immanuel Kant Baltic Federal University, Laboratory for Synthetic biology, School of Life Sciences, Kaliningrad, e- \\ mail: otuchina@kantiana.ru
}

Astrocytes are morphologically and functionally heterogeneous cell population. Most studies are focused on changes in glia during the development of neurodegenerative diseases, however, the heterogeneity of cells in the physiological state and normal aging is also of great interest for understanding neuron-glial interactions. The aim of this study was to investigate regionally heterogeneous expression of two commonly used astrocytic markers: glial fibrillary acid protein (GFAP) and glutamine synthetase (GS) in vitro. Astrocytes isolated from the brainstem are divided into two populations: GFAP- and GFAP +, the latter is characterized by increased expression compared to cortical and hippocampal astrocytes. With respect to GS expression, astrocytes from the cerebral cortex show a significantly higher level of GS compared to astrocytes from the hippocampus and brainstem. Moreover, there is a positive correlation between GFAP and GS expression. Thus, our data indicate that astrocytes from the cerebral cortex, hippocampus and brainstem are heterogeneous with respect to GFAP and GS expression.

Keywords: glial cells, cerebral cortex, hippocampus, brainstem, GFAP, GS.

До недавнего времени нейроны считали основными функциональными единицами нервной системы, тогда как клетки глии - лишь опорными и вспомогательными элементами.

Однако за последние несколько лет эта концепция сильно изменилась. Исследования 
показывают, что глиальные клетки не просто образуют опорный каркас нервной ткани, но также обеспечивают нормальное функционирование нейронов: поддерживают баланс ионов, регулируют уровень нейротрансмиттеров в синаптической щели, выделяют глиотрансмиттеры, участвуют в энергетическом обмене и образовании гематоэнцефалического барьера, вырабатывают цитокины и факторы роста, способствуют формированию нейрональных сетей, удаляя малоактивные синапсы во время развития мозга [1]. Из всех глиальных клеток астроциты наиболее многочисленны и выполняют самые разнообразные функции. Исторически астроциты подразделяют на два типа, основываясь на морфологии и расположении: протоплазматические и фиброзные, находящиеся в сером и белом веществе соответственно. Но результаты последних исследований показывают, что гетерогенность астроглии не ограничивается этими двумя фенотипами.

Основываясь на экспериментальных данных, S. Miller с соавт. (2018) показали, что при развитии нейродегенеративных заболеваний, таких как болезни Паркинсона и Альцгеймера, профиль астроцитов изменяется, в частности снижается экспрессия калиевых каналов Kir4.1 и транспортера глутамата Glt1, а экспрессия глиального фибриллярного кислого белка (GFAP) повышается, в то время как при эпилепсии астроглия характеризуется пониженной экспрессией Kir4.1, Glt1, а также синтетазы глутамина (GS) и каналов AQP4 [2]. При развитии процессов нейровоспаления профиль астроцитов тоже изменяется. S. Liddelow с соавт. (2017) продемонстрировали, что под воздействием липополисахарида астроциты изменяют фенотип на нейротоксический (A1), который характеризуется повышенной экспрессией компонентов системы комплемента, в частности С3, но это происходит только в том случае, если микроглиальные клетки тоже активированы; в то время как нейропротекторный фенотип (A2) характеризуется повышенной экспрессией S100a10, Stat3 и CD14 [3]. Таким образом, молекулярный профиль глиальных клеток изменяется под воздействием различных внутренних и внешних факторов, и можно выделить фенотипы астроцитов, характерные для того или иного патологического состояния.

Большинство исследований посвящено изменениям глии при развитии нейродегенеративных заболеваний [4], процессов нейровоспаления, сопутствующих стрессовым расстройствам [5] или развитию системной иммунной реакции. Однако гетерогенность астроцитов в физиологическом состоянии и при нормальном старении также представляет большой интерес. Аналогично нейронам, которые различаются по морфологии, нейротрансмиттерному профилю и функциональным особенностям в разных регионах мозга, 
астроциты тоже демонстрируют морфологические и функциональные отличия. Например, региональной гетерогенностью экспрессии отличаются щелевые контакты астроцитов, состоящие из белков коннексинов CX43 и СX30: CX43 экспрессируется повсеместно в мозге, но в особенности в гиппокампе, в то время как СX30 - преимущественно в таламусе и мозжечке, значительно меньше - в коре и гиппокампе [6]. Даже в отношении белка цитоскелета GFAP существуют различия: в белом веществе чаще встречаются астроциты, для которых характерна высокая экспрессия GFAP (GFAP ${ }^{\text {hi }}$, в то время как в сером веществе большинство астроцитов экспрессируют этот белок в меньшем количестве (GFAP ${ }^{\text {low }}$ ) [7]. Более того, астроциты демонстрируют гетерогенность внутри одного региона. Так, в гиппокампе мыши было обнаружено две популяции: так называемые пассивные астроциты, которые экспрессируют только транспортеры глутамата, и активные, для которых характерно наличие как транспортеров, так и рецепторов глутамата. Таким образом, астроциты представляют собой гетерогенную популяцию глиальных клеток как в морфологическом, так и в функциональном отношении. Исследование молекулярных механизмов этой гетерогенности необходимо для лучшего понимания нейрон-глиальных взаимодействий в здоровом мозге, а также при развитии различных патологических состояний. Целью настоящего исследования было изучение региональной гетерогенности астроцитов мозга крысы в отношении экспрессии двух наиболее часто используемых астроцитарных маркеров (GFAP и GS) in vitro.

\section{Материалы и методы исследования}

Для приготовления культур клеток использовали 3-дневных (Р3) крыс Rattus norvegicus domestica. Животных содержали в стандартных условиях вивария при световом режиме 12/12, доступе к корму и воде ad libitum. Эксперименты проводили в соответствии с этическими правилами работы с животными (приказ МЗ и СР РФ № 708н от 23.08.2010 г. «Правила лабораторной практики в Российской Федерации» и «European Convention for the Protection of Vertebral Animals Used for Experimental and Other Scientific Purposes». CETS No. 123). В работе использовали оборудование и реактивы для приготовления культур от ThermoFisher Scientific (США), реактивы для гистологии от Sigma Aldrich (США), антитела для иммуногистохимии и среду для приготовления препаратов от Аbcam (Великобритания).

После декапитации проводили выделение регионов мозга (церебральная кора, гиппокамп, ствол мозга) в сбалансированном солевом растворе Хэнкса на льду. Полученные суспензии клеток пропускали через фильтр и помещали во флаконы, предварительно 
обработанные полилизином. Клетки выращивали в питательной среде DMEM-GlutaMAX, содержащей $10 \%$ бычьей сыворотки, а также пенициллин-стрептомицин. Смешанную глиальную культуру инкубировали в течение 11-14 дней при $+37^{\circ} \mathrm{C}$ в инкубаторе в атмосфере $5 \% \mathrm{CO}_{2}$ и 95\% воздуха, питательная среда менялась два раза в неделю. Клетки микроглии и олигодендроцитов отделяли от астроцитов с помощью шейкера (250 об/мин, при $\left.+37^{\circ} \mathrm{C}\right)$, после чего культуру чистых астроцитов выращивали в течение 72 ч при $+37^{\circ} \mathrm{C}$ в инкубаторе в атмосфере $5 \% \mathrm{CO}_{2}$ и 95\% воздуха и рассаживали на покровные стекла. Затем клетки на стеклах фиксировали 4\%-ным параформальдегидом на натрий-фосфатном буфере, промывали 3 раза буфером по 10 мин и инкубировали 8 ч в 5\%-ном растворе бычьего альбумина с добавлением $0,01 \%$ тритона $\mathrm{X}$ в течение 10 ч при $+4^{\circ} \mathrm{C}$. По завершении инкубации проводили иммуногистохимическое окрашивание с помощью поликлональных антител кролика к GFAP (ab7260) и моноклональных антител мыши к GS (ab64613) в концентрации 1:1000 в течение 10 ч при $+4^{\circ} \mathrm{C}$ с последующей инкубацией со вторичными антителами к кролику с флуоресцентной меткой Alexa 647 (ab150075) и к мыши с флуоресцентной меткой Alexa 555 (ab150114) в концентрации 1:1000 в течение 2 ч при комнатной температуре на шейкере. Препараты окрашенных клеток готовили по общепринятой методике, в качестве заливочной среды использовали Fluoroshield c добавлением маркера нуклеиновых кислот DAPI.

Полученные препараты сканировали на конфокальном лазерном микроскопе LSM 780 (Zeiss, Германия) с использованием ультрафиолетового, аргонового и гелий-неонового лазеров. Всего было сделано по 15 фотографий в режиме z-stack для каждого региона мозга. Подсчет интенсивности флуоресценции проводили в режиме maximum intensity projection в программе ImageJ с учетом параметров «площадь клетки» и «интегрированная плотность». Скорректированную интенсивность флуоресценции для каждой клетки определяли отдельно по двум каналам и с учетом площади клетки и интенсивности флуоресценции фона. Измерения уровня флуоресценции GFAP и GS проводили на 200 клетках из каждого региона мозга. Статистическую обработку полученных данных осуществляли в программе GraphPad Prism 8 с использованием one-way ANOVA с последующим Sidak тестом для множественных сравнений. Статистически значимыми считали различия при $\mathrm{p} \leq 0,05$. Анализ корреляции проводился с помощью вычисления коэффициента Пирсона.

\section{Результаты исследования и их обсуждение}

Астроциты, выделенные из разных регионов мозга, демонстрируют гетерогенность 
экспрессии GFAP и GS in vitro (рис. A-B). При анализе интенсивности флуоресценции было обнаружено, что между астроцитами из церебральной коры и гиппокампа нет статистически значимых различий в количестве белка GFAP $(\mathrm{p}=0,09)$, в то время как в астроцитах из ствола мозга экспрессия GFAP значительно выше $(p<0,0001)$ (рис. Г). При этом следует отметить, что если в культурах коры и гиппокампа практически все клетки можно было охарактеризовать как GFAP+, то в культуре из ствола мозга наблюдалось большое количество GFAP-. Отсутствие GFAP не позволяет сделать однозначный вывод о принадлежности этих клеток к тому или иному типу, поэтому они не учитывались при анализе флуоресценции. Однако, если ранее в исследованиях GFAP рассматривали как универсальный маркер для всех астроцитов, на сегодняшний день известно, что существуют популяции астроцитов, не экспрессирующие этот белок. Более того, было показано, что в культурах клеток из мозга взрослого человека количество GFAP+ невелико, на экспрессию этого белка в культуре могут влиять концентрация сыворотки в питательной среде и эпигенетические модификации, как, например, в случае GFAP- клеток глиомы человека. Таким образом, астроциты, выделенные из ствола мозга, вероятно, подразделяются на две большие популяции in vitro: GFAP- и GFAP+, причем последние характеризуются повышенной экспрессией белка по сравнению с астроцитами, выделенными из церебральной коры и гиппокампа.

GFAP представляет собой белок промежуточных филаментов цитоскелета, основной функцией которого считается поддержание формы клетки. Интересно, что при подсчете площади клеток в культуре из трех регионов мозга значимой разницы между площадью астроцитов из церебральной коры и гиппокампа не выявлено, в то время как GFAP+ астроциты из ствола мозга значительно крупнее. Помимо механической функции поддержания формы клетки, GFAP также принимает участие в митозе, процессах миелинизации [8], взаимодействует с белками MEN1 и PSEN1. Последний, как предполагается, играет роль в накоплении $\beta$-амилоида и, возможно, связан с прогрессированием болезни Альцгеймера [9]. Мутации в гене GFAP приводят к развитию болезни Александера, которая характеризуется формированием волокон Розенталя, состоящих из иррегулярных скоплений филаментов GFAP и некоторых других белков, а также демиелинизацией и повышенным уровнем аутофагии. У мышей с нуль-мутацией по GFAP тоже наблюдается демиелинизация, а кроме того - нарушение функционирования гематоэнцефалического барьера (ГЭБ) [8]. Возможно, что в обоих случаях демиелинизация 
является следствием повышенной проницаемости ГЭБ, которая в свою очередь является следствием отсутствия GFAP или абнормальностей в его структуре.

Интересно, что мутации GFAP также приводят к нарушениям взаимодействия между астроцитами и нейронами. Известно, что астроциты в сером веществе характеризуются пониженной экспрессией GFAP по сравнению с астроцитами из белого вещества [7], и тогда можно предположить, что, так как в стволе мозга много проводящих путей, в нашей культуре большая часть GFAP+ астроцитов представляют собой клетки из белого вещества мозга. При травме мозга, развитии нейродегенеративных заболеваний или процессов нейровоспаления происходят изменение морфологии астроцитов, увеличение размеров клеток и увеличение количества GFAP [3]. Можно предположить, что астроциты из ствола мозга реагируют посредством увеличения экспрессии GFAP на какие-то факторы среды, например на компоненты сыворотки, то есть являются к этим компонентам более чувствительными, чем клетки из других регионов мозга.

Также стоит отметить, что существуют несколько изоформ GFAP: $\alpha, \beta, \gamma, \delta / \varepsilon, \kappa, \Delta 135$, $\Delta 164, \Delta$ exon6, $\Delta$ exon $7, \zeta[10]$, и вполне возможно, что с помощью антител, использованных в настоящей работе, были идентифицированы не все изоформы, а только те, которые наиболее полно представлены в астроцитах из ствола мозга. Таким образом, если раньше GFAP рассматривали исключительно как компонент цитоскелета и астроцитарный маркер, на сегодняшний день очевидно, что этот белок связан со многими жизненно важными функциями. Астроциты, выделенные из ствола мозга крысы, отличаются от астроцитов из коры и гиппокампа более высокой экспрессией GFAP, которая либо конститутивно высокая для этого региона мозга, либо является следствием региональной гетерогенности в чувствительности астроцитов к условиям in vitro.

Анализ интенсивности флуоресценции в отношении количества синтетазы глутамина (GS) in vitro показал, что астроциты из церебральной коры демонстрируют существенно более высокий уровень GS по сравнению с астроцитами из гиппокампа $(p=0,038)$ и ствола мозга ( $<0,0001)$ (рис. Д). При этом все GFAP+ клетки также можно охарактеризовать как GS+, хотя уровень синтетазы глутамина варьируется. Глутамат - основной возбуждающий нейротрансмиттер в ЦНС, и его концентрация во внеклеточном пространстве поддерживается на низком уровне благодаря работе астроцитарных транспортеров. GS в астроцитах синтезирует глутамин из потенциально токсичного в высоких концентрациях глутамата, при этом принимая участие в обезвреживании ионов аммония в нервной ткани. 
Было показано, что при отсутствии астроцитов культивируемые нейроны церебральной коры крысы значительно чаще погибают от эксайтотоксичности, вызванной чрезмерно высоким уровнем глутамата. Более того, при отсутствии астроцитов и/или недостаточном количестве глутамина в питательной среде нейроны начинают также экспрессировать GS [11], что указывает на важность этого фермента в метаболизме глутамата и аммония.

При некоторых патологических состояниях наблюдаются изменения экспрессии GS в астроцитах, однако характер изменений зависит от исследуемого региона. Например, при шизофрении происходит снижение экспрессии GS в церебральной коре, в то время как в таламусе экспрессия значительно повышается по сравнению с контролем [12]. При эпилепсии астроциты в гиппокампе демонстрируют пониженную экспрессию GS, что, вероятно, способствует поддержанию высокого уровня глутамата во внеклеточном пространстве и возникновению приступов. В моделях индуцированной гипераммониемии астроциты, находящиеся в непосредственной близости от глутаматергических нейронов, претерпевают морфологические изменения (происходят отек тела и отростков и общее увеличение площади клетки), а также компенсаторное увеличение экспрессии GS [13]. Так как ионы аммония свободно проникают через ГЭБ в паренхиму мозга, увеличение количества синтетазы глутамина наблюдается и в астроцитарных отростках, находящихся в периваскулярном пространстве. Таким образом, изменения в экспрессии GS при различных патологических состояниях свидетельствуют об изменении нормального функционирования астроцитов, причем они могут носить как адаптивный, так и маладаптивный характер.

Региональная гетерогенность экспрессии транспортеров, рецепторов и ферментов, участвующих в транспорте и метаболизме глутамата в здоровом мозге и при нормальном старении, еще мало изучена. Известно, что в церебральной коре и гиппокампе много глутаматергических нейронов и синапсов, поэтому повышенный уровень GS в астроцитах, выделенных из церебральной коры, по сравнению с уровнем GS в астроцитах в стволе мозга представляется логичным. Однако интересно, что астроциты в культуре сохраняют регионально гетерогенную экспрессию GS даже в отсутствие нейронов. Мы растили клетки на питательной среде, содержащей дипептид L-аланин-L-глутамин, который более стабилен в среде, чем L-глутамин, и позволяет избежать сильных колебаний в концентрации ионов аммония. Поэтому полученные нами данные свидетельствуют о регионально гетерогенном конститутивном уровне экспрессии GS в астроцитах in vitro. 

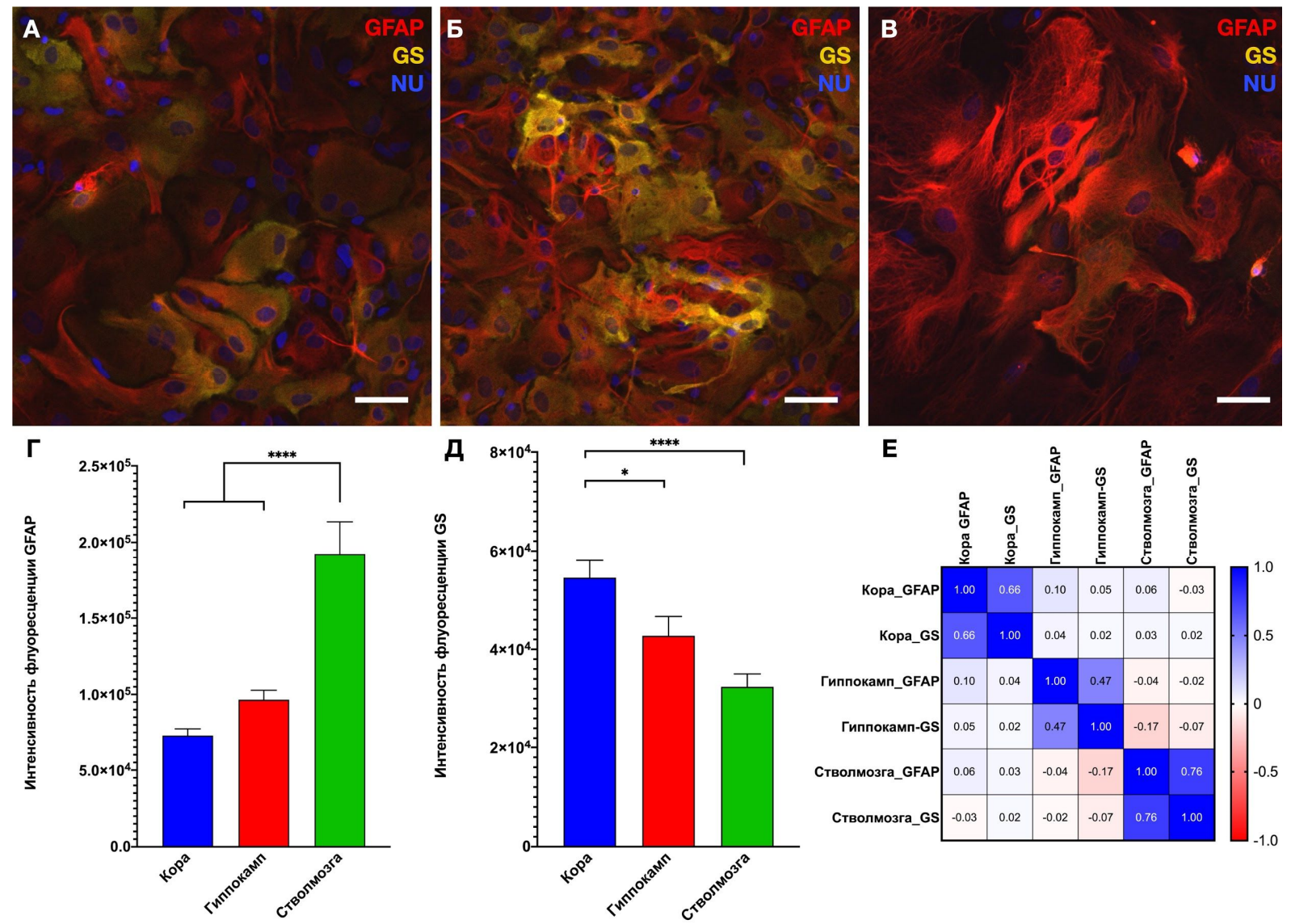

Региональная экспрессия GFAP (красный) и GS (желтый) в астроцитах из церебральной коры (A), гиппокампа (Б) и ствола мозга (B). NU (синий) - DAPI-маркер нуклеиновых кислот. Масштаб 50 мкм. Г, Д-интенсивность флуоресценции GFAP (Г) и GS (Д) в астроцитах из церебральной коры, гиппокампа и ствола мозга (ANOVA и Sidak mecm).

\section{E - Тепловая карта коррелячии экспрессии GFAP и GS}

Интересно, что при анализе интенсивности флуоресценции между экспрессией GFAP и GS наблюдается положительная корреляция для астроцитов из церебральной коры $(\mathrm{r}=0,66)$, гиппокампа $(\mathrm{r}=0,47)$ и ствола мозга $(\mathrm{r}=0,76)$ (рис. Е). Исследования показывают, что активация рецепторов глутамата на астроцитах стимулирует фосфорилирование GFAP как в культуре клеток, так и в переживающих срезах [14]. Предполагается, что долговременная стимуляция глутаматом приводит к реорганизации цитоскелета клетки и, возможно, к изменению функционального состояния астроцитов. При этом увеличение концентрации глутамата во внеклеточном пространстве вызывает увеличение экспрессии GS. Корреляция экспрессии GFAP и GS наблюдается в условиях гипераммониемии [15], хотя молекулярные 
механизмы регуляции экспрессии этих белков являются предметом дискуссии. Таким образом, наши данные свидетельствуют о том, что астроциты из церебральной коры, гиппокампа и ствола мозга регионально гетерогенны в отношении экспрессии GFAP и GS in vitro.

\section{Заключение}

Астроциты демонстрируют региональную гетерогенность экспрессии GFAP и GS in vitro. Астроциты, выделенные из ствола мозга, отличаются от астроглии из коры и гиппокампа более высокой экспрессией GFAP, которая либо конститутивно высокая для этого региона мозга, что может быть связано с большим числом GFAPhi фиброзных астроцитов, либо является следствием региональной гетерогенности в чувствительности астроцитов к условиям in vitro. В отношении GS анализ флуоресценции показал, что астроциты из церебральной коры демонстрируют существенно более высокий уровень синтетазы глутамина по сравнению с астроцитами из гиппокампа и ствола мозга, что может быть связано с большим числом глутаматергических синапсов. При этом между экспрессией GFAP и GS наблюдается положительная корреляция для всех исследованных регионов мозга. Таким образом, астроциты представляют собой гетерогенную популяцию глиальных клеток, и исследование молекулярных механизмов этой гетерогенности необходимо для лучшего понимания нейрон-глиальных взаимодействий в здоровом мозге, а также при развитии различных патологических состояний.

\section{Список литературы}

1. Kugelberg E. Microglia maintain optimal synapse density. Nature Reviews Immunology. 2014. vol. 14. P. 138. DOI: 10.1038/nri3635.

2. Miller S.J. Astrocyte heterogeneity in the adult central nervous system. Frontiers in Cellular Neuroscience. 2018. vol. 11. no. 59. P. 401. DOI: 10.3389/fncel.2018.00401.

3. Liddelow S.A., Guttenplan K.A., Clarke L.E., Bennett F.C., Bohlen C.J., Schirmer L., Bennett M.L., Münch A.E., Chung W.-S., Peterson T.C., Wilton D.K., Frouin A., Napier B.A., Panicker N., Kumar M., Buckwalter M.S., Rowitch D.H., Dawson V.L., Dawson T.M., Stevens B., Barres B.A. Neurotoxic reactive astrocytes are induced by activated microglia. Nature. 2017. vol. 541. P. 481-487. DOI: 10.1038/nature21029.

4. Prà I.D., Armato U., Chiarini A. Astrocytes' role in Alzheimer's disease neurodegeneration. 
In: Astrocyte - Physiology and Pathology. Intech Open Science. 2018. P: 119-137. DOI: 10.5772/intechopen.72974.

5. Тучина О.П., Сидорова М.В., Туркин А.В., Швайко Д.А., Шалагинова И.Г., Ваколюк И.А. Молекулярные механизмы инициации и развития нейровоспаления в модели посттравматического стрессового расстройства // Гены и клетки. 2018. Т. 13. № 2. С. 47-55. DOI: $10.23868 / 201808019$.

6. Boisvert M.M., Erikson G.A., Shokhirev M.N., Allen N.J. The aging astrocyte transcriptome from multiple regions of the mouse brain. Cell Reports. 2018. vol. 22. P. 269-285. DOI: 10.1016/j.celrep.2017.12.039.

7. Cahoy J.D., Emery B., Kaushal A., Foo L.C., Zamanian J.L., Christopherson K.S., Xing Y., Lubischer J.L., Krieg P.A., Krupenko S.A., Thompson W.J., Barres B.A. A transcriptome database for astrocytes, neurons, and oligodendrocytes: a new resource for understanding brain development and function. Journal of Neuroscience. 2008. vol. 28. no. 1. P. 264-278. DOI: 10.1523/JNEUROSCI.4178-07.2008.

8. Brenner M. Role of GFAP in CNS injuries. Neuroscience Letters. 2014. vol. 565. P. 7-13. DOI: $10.1016 /$ j.neulet.2014.01.055.

9. Walsh D.M., Selkoe D.J. Amyloid $\beta$-protein and beyond: the path forward in Alzheimer's disease. Current Opinion in Neurobiology. 2020. vol. 61. P.116-124. DOI: 10.1016/j.conb.2020.02.003.

10. Middeldorp J., Hol E.M. GFAP in health and disease. Progress in Neurobiology. 2011. vol. 93. no. 3. P. 421-443. DOI: 10.1016/j.pneurobio.2011.01.005.

11. Fernandes S.P., Dringen R., Lawen A., Robinson S.R. Neurones express glutamine synthetase when deprived of glutamine or interaction with astrocytes. Journal of Neurochemistry. 2010. vol. 114. no. 5. P. 1527-1536 DOI: 10.1111/j.1471-4159.2010.06869.x.

12. Bruneau E.G., McCullumsmith R.E., Haroutunian V., Davis K.L., Meador-Woodruff J.H. Increased expression of glutaminase and glutamine synthetase mRNA in the thalamus in schizophrenia. Schizophrenia Research. 2005. vol. 75. no. 1. P. 27-34. DOI: 10.1016/j.schres.2004.12.012.

13. Suárez I., Bodega G., Fernández B. Glutamine synthetase in brain: effect of ammonia. Neurochemistry International. 2002. vol. 41. no. 2-3. P. 123-142. DOI: 10.1016/s01970186(02)00033-5.

14. Kommers T., Vinadé L., Pereira C., Gonçalves C.A., Wofchuk S., Rodnight R. Regulation 
of the phosphorylation of glial fibrillary acidic protein (GFAP) by glutamate and calcium ions in slices of immature rat spinal cord: comparison with immature hippocampus. Neuroscience Letters. 1998. vol. 248. no. 2. P. 141-143. DOI: 10.1016/s0304-3940(98)00340-1.

15. Mani R., Natesan V., Arumugam R. Neuroprotective effect of chrysin on hyperammonemia mediated neuroinflammatory responses and altered expression of astrocytic protein in the hippocampus. Biomedicine Pharmacotherapy. 2017. vol. 88. P. 762-769. DOI: 10.1016/j.biopha.2017.01.081. 